\title{
LA FUNCIONALIDAD DE LO ILEGAL EN LAS EXPERIENCIAS DE MIGRANTES MEXICANOS
}

\author{
Edel J. Fresneda ${ }^{a}$
}

Fecha de recepción: 18 de junio de 2019. Fecha de aceptación: 20 de noviembre de 2019.

$$
\text { http://doi.org/10.22201/iiec.20078951e.2020.201.69430 }
$$

Resumen. Este artículo profundiza sobre el análisis de la ilegalidad en la migración desde la perspectiva migrante. Para ello, se analizaron prácticas históricas -usuales y asimiladas- en grupos seleccionados de migrantes mexicanos de acuerdo a su condición migratoria y lugar de asentamiento. La tesis que a continuación se expone es que esa ilegalidad tiene un carácter funcional para la reproducción de la trayectoria migrante. Se demuestra usando un análisis comparativo que las decisiones de los migrantes les permiten integrar sus trayectorias en dos contextos que evidencian un desarrollo desigual. Integración que determina la funcionalidad de sus actos de manera independiente a la existencia de políticas migratorias restrictivas en los contextos de Estado-nación.

Palabras clave: migración ilegal; desarrollo desigual; política migratoria; vulnerabilidad; México; Estados Unidos.

Clasificación JEL: F22; O15; R23.

\section{THE FUNCTIONALITY OF ILLEGALITY IN THE EXPERIENCES OF MEXICAN MIGRANTS}

\begin{abstract}
This paper delves into an analysis of illegality in migration, from a migrant perspective. To do this, established and assimilated historical practices in selected groups of Mexican migrants were analyzed according to immigration status and settlement area. The argument presented here is that illegality has a functional character for the reproduction of the migrant trajectory. This is demonstrated using a comparative analysis of the way migrants' decisions allow them to integrate their trajectories into two contexts which show unequal development. Such integration determines its functionality independently of the existence of restrictive migration policies in nationstate contexts.
\end{abstract}

Key Words: illegal migration; unequal development; migration policy; vulnerability; Mexico; United States.

\footnotetext{
${ }^{a}$ Centro de Investigaciones y Estudios Superiores en Antropología Social, conacyt, México. Correo electrónico: edel.fresneda@gmail.com
} 


\section{INTRODUCCIÓN}

En los últimos años, como consecuencia del aumento de migrantes y del reforzamiento de una política restrictiva en países de asentamiento, se realizaron numerosos trabajos sobre la migración indocumentada. Un aspecto con frecuencia referido fue el problema de utilizar el término "ilegal" para describir las prácticas de los migrantes; por la connotación que éste tiene en la opinión pública como una percepción negativa sobre este tipo de migración (Massey y Capoferro, 2006; Faist y Gerdes, 2006). No obstante, bajo ese argumento -que hace énfasis sobre el sesgo discriminatorio que estimula esa acepción en ambientes restrictivos-, subyace una erosión epistémica que delimita la pertinencia del mismo término para describir prácticas históricas, usuales y asimiladas por los que emigran; allí donde las experiencias de ilegalidad son funcionales a las estrategias de reproducción de los mismos sujetos e independientes al reforzamiento de las políticas migratorias. Funcionales, porque esa condición les permite a los migrantes reinsertarse en otros contextos-percibidos por las diásporas como más favorables para su reproducción social-, desde las condiciones de vulnerabilidad que parten.

Dentro de una discusión sobre migración y desarrollo, esto último significa que con independencia de la severidad o de la selectividad manifiesta en una política migratoria, las prácticas "ilegales" son una secuela de desequilibrios estructurales asociados al proceso histórico y en desventaja de integración entre las naciones. Desequilibrios que consienten grados diversos de marginación para sectores vulnerables. Y todo lo cual plantea un reto para la efectividad de las políticas restrictivas a nivel nacional.

Bajo este tenor, resulta sustantivo ahondar en un enfoque que permita resolver conflictos metodológicos sobre la pertinencia de ese término para describir las acciones relacionadas con la reinserción de los migrantes en distintos contextos. Un enfoque que es relevante y necesario, porque ese carácter funcional permite describir prácticas ilegales en distintas situaciones migratorias y de manera bidireccional, tanto en países de origen como de asentamiento; ampliándose así el examen cualitativo sobre ese tipo de experiencias en la migración. Dicho en otras palabras, la ilegalidad en la migración no se circunscribe a la condición migratoria en los países de destino exclusivamente, sino que abarca un amplio espectro de formas y prácticas históricas, usuales y asimiladas por los migrantes que les son funcionales a partir de las condiciones socioeconómicas donde se desenvuelven.

De esta forma, es pertinente plantear el análisis de las estrategias de movilidad y de reinserción socioeconómica, que se elaboran para cambiar condi- 
ciones estructurales de vulnerabilidad, que prevalecen en los lugares de origen y asentamiento y que no se correlacionan con prácticas de criminalidad. Así, también se plantea la necesidad de que existan políticas migratorias transnacionales que, lejos de hacer hincapié en estrategias restrictivas en el ámbito doméstico, busquen atender las problemáticas prevalecientes en escenarios de integración global, donde las disparidades del desarrollo desigual refuerzan la migración.

El término ilegal aquí se explica como una transgresión que hacen los migrantes -en ocasiones consciente y en otras forzada-, de normas nomológicas -principios, leyes o preceptos-, que regulan las dinámicas socioeconómicas de los estados-nación que se involucran por medio del acto de migrar. Esto último, supone un ajuste en el uso del término "ilegal" para describir las prácticas que funcionalmente les permiten a los migrantes viabilizar su reinserción en otros contextos y como parte de su estrategia de reproducción social. Ajuste que admite un acercamiento científico - sin el sesgo ético que supone el uso del término en un ámbito restrictivo-, a cuáles prácticas ilegales tipifican un flujo migratorio en función de las metas o de los objetivos establecidos en la estrategia de movilidad como: acceder a derechos, articular procesos socioeconómicos en diferentes contextos u obtener beneficios considerando la disparidad entre desiguales espacios.

En este sentido, no es ocioso subrayar que, el uso aquí del adjetivo "ilegal" para referir las experiencias y prácticas de los migrantes, no refuerza la connotación que tiene en el ámbito de los países que quieren controlar la migración indocumentada; donde es pertinente la discusión ética sobre la utilización de este epíteto -como se verá más adelante.

Así pues, se parte de la hipótesis de que cuando la ilegalidad está presente en la trayectoria migrante, consiente procesos de articulación entre contextos de desarrollo desigual; reflejando de esta forma el condicionamiento que tienen los éxodos a partir de las brechas de desarrollo entre los países y, en consecuencia, siendo un efecto de la evolución histórica que han tenido las políticas migratorias para intervenir en la migración sin atender a condicionamientos supranacionales que inciden en el fenómeno. Y, aunque la siguiente no es una idea que se desarrollará en este trabajo en particular, esta hipótesis resulta relevante porque revela que el carácter funcional de lo ilegal en la migración, extiende -sobre todo por los riesgos implícitos en esa condición-, la vulnerabilidad que enfrentan los migrantes en su lugar de origen a un espacio transnacional. 
Para corroborar la hipótesis anterior, se desarrolló una investigación cualitativa -en la que se aplicaron entrevistas semiestructuradas ${ }^{1}$ en su mayoría-, a una muestra no representativa de migrantes mexicanos que manifestaron experiencias de ilegalidad en cuanto a las prácticas usuales de articulación de sus vidas en diferentes contextos. Se exploró en la narrativa de sus experiencias cómo en sus propias trayectorias, esa ilegalidad -percibida por ellos-, tuvo un carácter funcional. A partir de las mismas experiencias, se conformaron dos grupos de análisis: 1) migrantes que por alguna circunstancia nacieron en Estados Unidos y regresaron a México; 2) migrantes que nacieron en México y fueron a Estados Unidos. Es importante realizar una última acotación metodológica y es que este estudio se realizó bajo la perspectiva teórica explicada por Zenteno y Massey (1999) quienes argumentan cómo es relevante el análisis particular que conlleva a la determinación de problemáticas no contempladas en la generalidad de algunos estudios.

En adelante, la estructura de este artículo se divide en tres secciones principales. En la primera de ellas, se utilizan argumentos teóricos relevantes para analizar la ilegalidad en la trayectoria migrante, como una consecuencia transnacional de la integración desigual entre estrategias de desarrollo nacionales y muy vinculadas entre sí. En la segunda sección, se profundiza en cuáles son las prácticas, usos y vivencias que hacen pervivir la condición de ilegalidad y su carácter funcional en los procesos de integración binacional de los migrantes. Y, la tercera sección, se proponen conclusiones que lejos de cerrar el análisis, buscan promover un debate epistemológico y teórico sobre esta importante cuestión.

\section{ARGUMENTOS TEÓRICOS EN EL ESTUDIO DE LA ILEGALIDAD EN LA TRAYECTORIA MIGRANTE}

Para abordar el carácter de la ilegalidad en las experiencias de los migrantes mexicanos hacia Estados Unidos, resulta sustantivo considerar dos aspectos teóricos relevantes y que posicionan a este artículo en la discusión sobre migración y desarrollo. El primero de ellos es la consideración de que existe un condicionamiento a la migración exterior en México a partir de las divergencias en el desarrollo que manifiesta este país con respecto a Estados Unidos (Glick Schiller et al., 1995; Castels, 2014; Delgado Wise, 2018). Diferencias

1 Desarrolladas por un equipo de trabajo del Centro de Investigaciones y Estudios Superiores en Antropología Social (CIESAS) Occidente en 2015. 
que son más nítidas al nivel local y regional y que condicionan la trayectoria migrante sobre todo en los ámbitos fronterizos, donde las experiencias de ilegalidad en uno u otro sentido forman parte de la vida cotidiana de los migrantes.

El segundo es que con el crecimiento de la migración ilegal a Estados Unidos como consecuencia de ese condicionamiento $-\mathrm{y}$ con la habituación de esas experiencias de ilegalidad a partir de su funcionalidad-, en ese escenario se ha reforzado una política migratoria restrictiva que viene acompañada de una opinión pública negativa hacia este tipo de migración (Cornelius y Aguayo, 1978).

No obstante, este no es el único contexto donde se manifiestan esas experiencias. En dependencia de la propia trayectoria migrante se observan (como se verá más adelante) experiencias de ilegalidad también en México. Sobre todo, de aquellos migrantes que, una vez acreditada su legalidad ante la política migratoria restrictiva de Estados Unidos, por diversas causas quisieron mantener la articulación de sus vidas en territorio mexicano. En esto último influyó también una política migratoria mexicana que anteriormente era más coercitiva para después ser más incluyente.

Respecto al condicionamiento a la migración, en México existe un debate teórico y crítico -en la discusión migración y desarrollo-, que recalca la tesis de que esta migración es forzada por las condiciones de existencia que enfrentan los migrantes. Para Castels (2003 y 2014), la principal fuerza detrás de la migración es la inseguridad humana que surge a su vez de la desigualdad global.

El carácter perentorio de esa movilidad para los migrantes (migración forzada), se origina según Castels (2003) y Delgado Wise (2018) en la disparidad que existe en el desarrollo de los países involucrados en la migración. Bajo esa lógica, la "dependencia" (Furtado, 2001) de los países del sur hacia con los del norte -desde el punto de vista económico y político-, genera una interrelación en la que la desestabilización política y las crisis económicas refuerzan ese carácter decisivo que adquiere la migración para los sectores más vulnerables en los países de origen. A ello, además, contribuyen las políticas de ajuste estructural del Banco Mundial y del Fondo Monetario Internacional, según Castels (2003).

En este sentido, Castels (2003) explica que la restricción dirigida hacia los migrantes no deseados al ser vistos como riesgos en los países destino, es una política que busca contener -también- las consecuencias sociales de un esquema de desarrollo global desigual. Así también las prácticas de ilegalidad pueden ser vistas como una consecuencia de este tipo de desarrollo. 
Delgado Wise (2018) expone que existe una descontextualización en el análisis que predomina sobre la migración internacional -a la que denomina imperialismo metodológico-, al hacer énfasis en las diferencias salariales, el desplazamiento de trabajadores nativos, la ilegalidad y el resguardo fronterizo como aspectos relevantes para el contexto del país receptor. El mismo autor observa que, desde esas características, se fija una posición etnocentrista e individualista con una comprensión incompleta de la conexión entre migración y desarrollo, y propone considerar otras dimensiones analíticas que van más allá del estudio del impacto en los contextos de origen y destino de la migración: causas del flujo y el impacto en los migrantes y sus familias (Delgado Wise, 2018, pp. 17-19). Lo anterior, es un posicionamiento teórico importante desde el cual se elaboran las premisas aquí discutidas: la funcionalidad de la ilegalidad desde condicionamientos en el desarrollo desigual como una dimensión analítica.

En este sentido, al analizar las condiciones de desarrollo, Lomelí y Vázquez (2016) argumentan que existen al menos tres causas que mantienen el flujo migratorio mexicano:1) las reformas promovidas de cambio estructural, que generan bajas tasas de actividad económica y una concomitante insuficiencia en la creación de empleos formales; 2) la relativamente baja absorción del bono demográfico en el empleo, lo que afecta especialmente a una población en edad laboral y, 3) las históricas interrelaciones construidas por los migrantes que tienden a soslayar las políticas migratorias restrictivas.

Según Roldán (2015), a raíz de la formulación del TLCAN se integraron comisiones tanto en Estados Unidos como en México que, de manera conjunta, buscaron explicar el flujo migratorio indocumentado entre ambos países. Un resultado importante de este trabajo fue un informe entregado al gobierno mexicano en la década de los noventa del siglo xx, en el que se determinaron como principales conclusiones las siguientes: a) la motivación principal de estos migrantes fue la búsqueda de oportunidades económicas y, b) la creación de empleos era una vía para disminuir ese flujo (Roldán, 2015, p. 105).

También, Aragonés y Salgado (2015) exponen que con el modelo neoliberal -impuesto por el Consenso de Washington-, la migración de trabajadores de México se integró a las demandas de desarrollo de Estados Unidos en la demanda de trabajadores de baja calificación, los cuales a través del tiempo han facilitado la disminución de los costos en sectores de la economía estadounidense; entre ellos, en el sector primario y en específico en la agricultura; en el sector industrial donde tienen un peso considerable las manufacturas; y en el sector terciario donde estos migrantes cubren los empleos de servicios. 
Por igual, Vázquez (2015) refiere cómo esta integración ha sido paulatina y ha reforzado los vínculos históricos tanto formales como informales entre ambas economías.

Una idea sustantiva respecto a lo antes descrito es que la migración ilegal es resultante de $-\mathrm{y}$ tiene un rol en- los procesos de integración socioeconómicos que han ocurrido en las últimas décadas entre las dos naciones, donde las dificultades del mercado laboral mexicano, las políticas de ajuste estructural y las demandas de trabajo desde Estados Unidos son factores relevantes. Bajo esta lógica, la elaboración de estrategias y acciones migratorias de naturaleza ilegal son respuestas decisivas en un contexto de vulnerabilidad donde existe una percepción tácita sobre los beneficios que implica un territorio respecto a otro espacio. En función de esos beneficios, se activan redes de apoyo y familiar que tienden a justificar las prácticas usuales e históricas de ilegalidad.

Frente a ese escenario, las políticas migratorias en los países destino tienden a controlar el "deseo de movilidad" (Castels, 2003, p. 15) selectivamente y, es en ese ámbito, donde crece el estereotipo sobre la migración ilegal, no obstante al intento de suavizar públicamente la clasificación sobre este tipo de migración (Castels, 2006; Massey y Capoferro, 2006; Munguía Salazar, 2015; Vázquez, 2015; Roldán, 2015; Galindo, 2019; Villarreal, 2019). Son en ese ambiente, los migrantes calificados y los trabajadores contratados lo más favorecidos, mientras que los menos, son los migrantes forzados, los trabajadores no calificados y sus dependientes. Sobre estos últimos tiende a recaer en su mayoría el estereotipo de ilegalidad al incurrir, de acuerdo a lo perentorio para ellos del acto de migrar, en prácticas que implican en efecto un estatus no acreditado legalmente bajo las condiciones que interpone la política migratoria.

Estos estereotipos -que como es conocido en los últimos años han caracterizado el escenario político de Estados Unidos-, favorecen el proceso de selección y exclusión de los migrantes que no acreditan estancia legal en el país. $\mathrm{Al}$ respecto, en su análisis sobre la relación lenguaje y sociedad en la prensa de circulación frecuente como son The New York Times y Los Angeles Times, Galindo (2019) explora el uso de adjetivos que aparentan disminuir el discurso discriminatorio, pero que de todas maneras refuerza una opinión pública desfavorable. Tal es el caso del uso del término indocumentado que a pesar de no ser "despectivo y denotar familiaridad" contiene una representación sobre los migrantes que no acreditan su condición legal en Estados Unidos.

La palabra ilegal, según Galindo (2019), encasilla a los migrantes como delincuentes. Y esto, es complejo, porque ante la legislación migratoria son los ilegales personas que incurren en un acto tipificado como transgresión legal, con excepción de algunos casos, no cometen actos criminales del fuero 
común. No obstante, en Estados Unidos ese carácter ilegal se canaliza a través de la opinión pública como un problema de seguridad nacional y se asocia a una criminalidad mucho más amplia que no se circunscribe a la transgresión migratoria en sí; llegando incluso a asociar ese carácter a otros epítetos. Se refuerza entonces en la prensa la "idea preconcebida de que los inmigrantes cometen delitos en Estados Unidos" (Galindo, 2019, p. 16). El inmigrante mexicano es especialmente denostado bajo estos prejuicios.

Para entender el alcance que tiene esa opinión pública, Roldán (2015) explica que el término ilegal -que por lo común se utiliza en aquel contextotiene una connotación política y un carácter jurídico. Según ella, esto hace referencia a la relación que se establece con el epíteto "delincuente", criminalizando así una migración laboral que incurre en faltas administrativas. Este es un fenómeno que también describió Castels (2003) al argumentar que no era sólo reconocible en Estados Unidos, sino también en Australia y la Unión Europea. El mismo autor, introdujo el término de "migración irregular" (Castels, 2014) para caracterizar este tipo de migración que es reclasificado por leyes y reglamentaciones selectivas. Vázquez (2015), por su parte, defiende el uso el término "migración indocumentada" para describir este tipo de migración.

Asimismo, Villareal (2019) explica que la residencia ilegal en Estados Unidos es un delito que tiene un carácter federal y es uno de los delitos con más cobertura en la prensa asociado de forma indirecta dentro del discurso político reciente con grupos de personas dedicados al contrabando de drogas y al tráfico de personas. Bajo este estigma, los migrantes son confinados a un ostracismo social que esconde sus contribuciones reales a la economía de la nación americana. Ese "destierro" es aceptado socialmente y es la base en la opinión pública de las deportaciones masivas de migrantes ilegales o indocumentados. Para Castels (2006) ese contexto que acompaña al control migratorio responde a lo inevitable de la circunstancia ilegal para movimientos humanos que no encuentran otra alternativa para su realización ante la regulación de las relaciones norte-sur (Castels, 2006, p. 44).

En tanto, Glick Schiller et al. (1995) reconocen que desde el sesgo de las políticas migratorias restrictivas se ha manifestado, además, un proceso que condiciona la asimilación de los migrantes bajo premisas de "lealtad" a un sistema político y económico específico; "validando el derecho de pertenecer de los migrantes y diferenciándolos de otros [...] bajo una dialéctica de inclusión y exclusión que los disciplina al ser objeto de escrutinio público" (Glick Schiller et al., 1995, p. 59), los procesos migratorios son condicionados por 
las políticas migratorias, ${ }^{2}$ influyendo tanto en lo relativo a la acreditación legal de migrantes seleccionados como a la diversificación de las acciones de esos migrantes, al concebir éstos soluciones para acceder a un contexto esencialmente restringido. En esa diversificación también ocurren actos de ilegalidad.

Massey y Capoferro (2006) ofrecen un ejemplo que ilustra de manera fehaciente lo descrito anteriormente. De acuerdo a estos autores, han existido históricamente dificultades para determinar el alcance de la migración ilegal en los países receptores. Un aspecto relevante en este sentido es que una proporción considerable de estos migrantes llegan a los países destino bajo una condición legal -como la visa de no inmigrante. "La violación posterior de esa condición hace imposible anticipar quiénes terminarán con un estatus ilegal" (Massey y Capoferro, 2006, p. 274). A ello se suma el hecho de que las naciones receptoras no llevan un registro de entradas y salidas. ${ }^{3}$

Otro punto relevante en este tenor es que las prácticas ilegales asociadas a la trayectoria migrante pueden tener un alcance trasnacional desde la acreditación legal en el contexto restrictivo, dada su funcionalidad para articular procesos de reproducción social en espacios nacionales diferenciados En el caso México-Estados Unidos, por ejemplo, las políticas selectivas de asimilación de migrantes han determinado - por medio de la acreditación legal de la residencia y la naturalización-, una tipología de migrante binacional que también establece estrategias que implican acciones ilegales, al intentar extender su propia trayectoria migrante y la influencia que ésta tiene en sus familias frente a normas o leyes prevalecientes en sus lugares de origen.

Teóricamente, Faist y Gerden (2006) explican que son las circunstancias históricas que caracterizan los flujos, las que han originado una tolerancia y resistencia hacia la doble nacionalidad como un proceso dependiente de la trayectoria migratoria (Faist y Gerden, 2006, p. 97). Dentro de esas circunstancias están las prácticas culturales y sociales de los migrantes y, también, la

Las políticas migratorias selectivas no son exclusivas de Estados Unidos en la región. También en países como Canadá y Argentina existe una historia de legislación restrictiva (Alvites, 2019). En el caso de Estados Unidos, es en la década de los ochenta del siglo xx cuando la legislación migratoria adquiere un carácter más restrictivo con la entrada en vigor de la Immigration Reform Control Act (IRCA) (Munguía Salazar, 2015). Bajo este escenario, el presidente Bill Clinton en 1996 determina un ajuste a la condición de "refugiado" para así frenar la migración ilegal -principalmente a raíz de la entrada masiva de cubanos y haitianos en el lustro anterior (Castels, 2003).

3 En Estados Unidos, estas imperfecciones están en litigio legal a partir de que el gobierno abandonó los controles de salida en 1957, desde entonces las autoridades no han conservado estadística alguna de las salidas de cualquier persona, con documentos o sin ellos (Massey y Capoferro, 2006, p. 274). 
evolución de las políticas migratorias dentro de intereses nacionales. Para estos autores, la doble nacionalidad refleja un proceso de integración entre: a) las intenciones en los países receptores de regularizar la migración y, $b$ ) los propósitos de los migrantes quienes buscan insertarse en dinámicas socio-laborales y económicas -mayormente-, que perciben como favorables.

La tolerancia a la doble nacionalidad es un proceso que le da un significado a la migración en la sociedad de acogida, al otorgarle congruencia legal al fenómeno de integración descrito antes. Empero, esa doble nacionalidad también le da significado al proceso migratorio en las sociedades de origen, al extender la potencialidad futura de emigrar a nuevos sujetos o permitir la integración de estrategias de vida entre dos países.

Esto es especialmente significativo para los migrantes que no son aptos para la selección establecida en las políticas, quienes buscan formas de adaptación al modelo restrictivo y utilizan la acreditación legal para extender la potencialidad de migrar y, con ello, acceder a mejores oportunidades de movilidad social en el futuro. Como se verá más adelante, esa integración entre los intereses de las políticas migratorias y los propósitos de los migrantes ocurre mediante estrategias que implican -en ocasiones- acciones ilegales, por ejemplo, declaraciones apócrifas sobre el lugar de residencia para obtener la nacionalidad; el arreglo matrimonial o el cruce de fronteras para dar a luz a futuros ciudadanos de Estados Unidos.

En este sentido, también desde un punto de vista teórico, Faist y Gerden (2006) determinan que desde ese proceso de integración dual -que puede germinar de manera circunstancial-, surge una "dependencia de la trayectoria" que se manifiesta más en el ámbito del migrante y sus propósitos de integración eficaz, pero también en lo relativo a las políticas migratorias que buscan ajustar las prácticas e historia de los sujetos que se movilizan entre las naciones. Esta dependencia significa: "que una vez que los actores políticos han empezado a moverse por cierta trayectoria -tolerando la doble nacionalidad bajo ciertas circunstancias, como en el caso de los hijos de matrimonios binacionales- existen todos los incentivos para continuar por el mismo camino y muy serios inconvenientes en dar marcha atrás" (Faist y Gerden, 2006, p. 100).

Según Faist y Gerden (2006), aunque existen estudios sobre cómo esa condición binacional resuelve conflictos entre gobernantes y gobernados, la binacionalidad desde la perspectiva de los migrantes ha sido menos explorada. Un aspecto relevante desde esa perspectiva, es cómo la aceptación en un contexto restrictivo por medio de la acreditación legal, disminuye las prácticas ilegales migratorias en ese ambiente, al mismo tiempo que abre nuevos procesos de integración hacia la sociedad de origen que pueden involucrar prácticas ilegales. 
Un epítome de lo ya descrito, es que el creciente auge de políticas migratorias restrictivas responde a los intereses prevalecientes en las sociedades de acogida. Estos intereses omiten la contribución real de los migrantes a esas sociedades; al mismo tiempo que obvian los distintos procesos de integración que existen entre las demandas de mano de obra barata y los intereses que sostienen el éxodo. Aun cuando se intenta restringir la entrada de migrantes no favorecidos, el "deseo de movilidad" que prevalece bajo las condiciones de integración norte-sur, condiciona el acceso a esas sociedades utilizando, al mismo tiempo, los mecanismos de acreditación legal y las estrategias clasificadas como ilegales por esas políticas.

Por ello, ese "derecho de pertenecer" que promueve la selectividad, no disminuye la migración ilegal. Tampoco la ampliación de la doble nacionalidad per se reduce esa tipología. Por el contrario, subsiste con relación a los intereses manifiestos en la trayectoria migrante, lo que significa una adaptación de los sujetos a las condiciones restrictivas para sostener el flujo migratorio en el tiempo. En ese complejo proceso, los migrantes enfrentan, además, los estereotipos que predominan en la sociedad de acogida.

\section{LA ILEGALIDAD EN USOS, PRÁCTICAS Y VIVENCIAS DE LOS MIGRANTES MEXICANOS}

La información correspondiente a las experiencias sobre ilegalidad se obtuvo mediante un estudio cualitativo donde predominó el método etnográfico, aplicando entrevistas semiestructuradas y con análisis de discurso en menor medida, a una muestra no representativa de 242 personas -incluyendo hombres y mujeres- radicadas tanto en Estados Unidos como en México (localizadas mediante la técnica de Bola de Nieve). ${ }^{4}$ Se elaboraron preguntas y breves cuestionarios que buscaron evidenciar, por una parte, la capacidad de agencia de los entrevistados y su interpretación sobre las decisiones que involucraron prácticas ilegales en sus trayectorias migrantes. Por otra parte, en ellas se consideraron como variables explicativas la evaluación de los entrevistados de su entorno de origen y la relevancia de las decisiones asociadas a experiencias de ilegalidad también en sus trayectorias. Asimismo, se indagó sobre la evaluación que hacían de esas experiencias respecto a los beneficios que percibieron en sus vidas. 
Un tema principal en las entrevistas fue profundizar en el cómo se manifestaba el proceso de integración desde la trayectoria migrante a procesos socioeconómicos en contextos de desarrollo desigual; adaptándose en algunos casos a la política migratoria selectiva prevaleciente en Estados Unidos y, en los otros, haciendo uso de la condición ilegal para lograr los propósitos relacionados con sus intereses. Dígase, el deseo de movilidad latente bajo las condiciones de integración norte-sur.

Una cuestión sustantiva a resaltar es que las prácticas asimiladas, históricas y usuales que refirieron los sujetos estudiados y que reflejaron ilegalidad para integrar la trayectoria migrante, no se circunscribieron al contexto con predominio de una política restrictiva que tipifica acciones en específico como "ilegales". Desde la perspectiva migrante, esas prácticas abarcaron complejos procesos que no sólo están relacionados con la acreditación de la estancia legal en Estados Unidos, sino que incluyen otros intereses como el aseguramiento familiar de la migración futura y el acceso a derechos y beneficios múltiples en ambos lados de la frontera. Esos intereses se manifiestan, tanto en aquellos migrantes que tienen una condición de estancia legal o son naturalizados en Estados Unidos (binacionales), como en los que no. Lo anterior da pie a aseverar que la "ilegalidad" en la migración mexicana tiene un carácter multifuncional.

La población objeto de estudio -que manifestó además rasgos de integración entre las dos sociedades-, se dividió en dos subgrupos principales: 1) el de migrantes que por alguna circunstancia nacieron en Estados Unidos y regresaron a México; 2) el de migrantes que nacieron en México y fueron a Estados Unidos por alguna razón. Quedaron fuera del análisis los migrantes que nacieron en Estados Unidos y permanecieron viviendo en ese país, porque en ellos fue visible la tendencia de desarticulación entre las dos sociedades a partir de: a) un rasgo de identidad estadounidense que prevaleció -aun cuando mantuvieron aspectos culturales relacionados con la identidad mexicana-, en detrimento de los lazos y redes que tenían sus antepasados migrantes con México y, $b$ ) ausencia de integración desde su lugar de residencia con procesos socioeconómicos en México. La atención a estas particularidades permitió observar características que usualmente no son contempladas en estudios generales sobre la migración indocumentada o ilegal, como se verá más adelante.

En el primero de los subgrupos: "migrantes que por alguna circunstancia nacieron en Estados Unidos y regresaron a México", es relevante el carácter binacional de los entrevistados. Esa condición se logró en su mayoría por nacimiento circunstancial en aquel país. En ellos, además, sobresale el retorno 
a México como parte de la integración de sus familias a las dinámicas socioeconómicas de ese territorio.

En este subgrupo se manifiesta una primera característica relativa a la funcionalidad de la ilegalidad como antecedente. Esto es, que el acto ilegal abre un proceso de migración legal en el futuro. Esto a partir de la sobrerrepresentación que tiene en este subgrupo la variable "nacionalidad por nacimiento" y teniendo en cuenta los antecedentes familiares respecto a la acreditación legal de la residencia en Estados Unidos. En la mayoría de los casos, esa ilegalidad se manifestó a través de la acción de cruzar las fronteras para el nacimiento sin tener permisos de residencia, visa o condición legal de estancia en aquel país. Con esa acción se aseguró a futuro, el acceso a derechos en la sociedad y economías estadounidenses a través de la nacionalidad de los entrevistados. Esa doble condición se había utilizado para extender el ciclo migratorio hacia los padres -que en primer lugar tomaron la decisión de que se naciera en Estados Unidos- y otros familiares directos. Esto constituye un ejemplo de la dependencia de la trayectoria migrante que surge a partir de un acto ilegal.

El carácter circunstancial del nacimiento en territorio estadounidense deja entrever al menos dos aspectos relevantes para el análisis de la migración desde México. El primero, que la acción de cruzar las fronteras para tal efecto en Estados Unidos, constituye una transgresión de las normas establecidas que en la mayoría de los casos es consciente en el caso de los progenitores. Práctica asimilada como una inversión a futuro -con una mayor representación en las regiones fronterizas-, en tanto ocurre un proceso de integración a largo plazo que amplía el ciclo de reproducción de la migración. El segundo, que al nacer en Estados Unidos, los sujetos adquieren una condición migratoria que refuerza la alternativa de integración en sus propias vidas entre procesos socioeconómicos de dos estados-nación. No obstante, en estos casos las variables de política y de identidad se mantuvieron asociadas a México a pesar de la condición migratoria.

Dentro de los principales usos que se le dio a esa nacionalidad por nacimiento, destaca la ampliación del ciclo migratorio hacia nuevos migrantes. Fue visible la tendencia a reproducir ese acto -tener hijos en Estados Unidos-, pero bajo condiciones legales que les permitía su nacionalidad. También fue notorio el mayor uso del pasaporte norteamericano como documento de identidad internacional; así como la reinserción al mercado laboral de Estados Unidos como una alternativa plausible después de explorar opciones laborales y culminar estudios en México. Lo anterior fue considerado mayormente como un privilegio. 
Sin embargo, un aspecto menos trabajado en estos ciclos y que fue una tendencia corroborada en este subgrupo, es que después del nacimiento, los padres retornaron a México donde desenvolvían su proceso de reproducción social y económica. Este regreso implicó que los nacidos en Estados Unidos antes de 1998 -cuando cambió la Ley de Nacionalidad-, no pudiesen revelar su ciudadanía porque antes de esa fecha no se permitía la doble nacionalidad. Ello derivó en otras prácticas ilegales que buscaron sobre todo la acreditación de la ciudadanía mexicana por medio la falsificación de actas de nacimiento con el fin de que los nacidos en Estados Unidos pudiesen acceder a los beneficios otorgados por el gobierno mexicano. Así, durante la trayectoria migrante de este subgrupo, principalmente la ilegalidad no se manifiesta en el cruce de fronteras en dirección hacia Estados Unidos sino en sentido contrario, es en territorio mexicano donde se revela la tendencia del uso de prácticas ilegales para ser acreditados como mexicanos y obtener acceso a bienes, servicios y derechos como el acceso a la educación y a los servicios de salud públicos.

Este singular fenómeno originó dificultades en la vida de las personas que viven en México bajo esa condición. Algunas relativas a la doble personalidad jurídica, sus patronímicos, contradicciones en su documentación de identidad, y la formalización en Estados Unidos del matrimonio civil realizado en México. Por último, un aspecto significativo del antecedente de las prácticas ilegales en este subgrupo es cómo las mismas están vinculadas con la migración de retorno que ocurre hacia México y donde tiene un peso considerable la deportación de los padres que se mantienen ilegales en aquel país.

En el caso del segundo subgrupo, "migrantes que nacieron en México y fueron a Estados Unidos por alguna razón", se observan diferencias importantes respecto al primero. Una es que en este grupo las prácticas de ilegalidad son heterogéneas y se vinculan a la trayectoria migrante. Otra es que las mismas prácticas están más asociadas al contexto restrictivo de la política migratoria de Estados Unidos y menos en México. Como rasgos distintivos son de destacar los siguientes: a) la integración en los procesos socioeconómicos entre los dos países es más precaria y circunstancial; porque, $b$ ) la acreditación legal en Estados Unidos está más relacionada a condiciones de residencia temporal y a situaciones irregulares.

En este subgrupo las prácticas de ilegalidad son heterogéneas porque dependen de la trayectoria migrante. Con relación a esta última, se observan tipologías relativas al lugar de asentamiento y la condición migratoria que ostentan. Tal es el caso de: 1) los que nacieron en México, lograron una condición legal en Estados Unidos y retornaron a su lugar de nacimiento; 2) los que nacieron en México y fueron a Estados Unidos bajo una condición irregular 
que no pudieron cambiar. ${ }^{5}$ La heterogeneidad de las prácticas de ilegalidad en este subgrupo es más visible en un análisis particular de esas tipologías.

"Los que nacieron en México, lograron una condición legal en Estados Unidos y retornaron a su lugar de nacimiento" manifestaron prácticas de ilegalidad asociadas al propósito de acreditar su condición migratoria en Estados Unidos. Estas prácticas fueron sobre todo realizar declaraciones apócrifas respecto a su lugar de residencia vigente -poseían Greencard aunque vivían en México-; los entrevistados refirieron que mantuvieron direcciones postales estadounidenses para conservar su residencia. Dentro de las principales causas de mantener su residencia habitual en México fueron conservar las propiedades, el trabajo, la familia, así como la edad, por lo que no consideraron oportuno empezar una nueva vida en la nación vecina.

Dicha transgresión consciente en declaraciones realizadas a autoridades sobre su lugar de residencia habitual permitió una integración entre ambas sociedades que incide en su reproducción social, relativas a lo siguiente: a la libre movilidad; a la obtención de la ciudadanía estadounidense por residencia de cinco años; al acceso a oportunidades de trabajo en el mismo país; a la transferencia de la condición de residencia temporal o permanente a familiares directos, entre otros.

Es la movilidad -dentro de esta tipología-, la mayor evidencia de integración entre los procesos socioeconómicos de los dos países. Sin embargo, a diferencia del primer subgrupo, esta integración ocurre en el corto y mediano plazo, donde el cruce de fronteras cotidiano es un aspecto de suma importancia. No obstante que el cruce cotidiano se observa en otras tipologías, aquí es relevante porque demuestra la funcionalidad del no cumplimiento de las condiciones que demanda la condición de residente en Estados Unidos para poner en práctica los propósitos de los sujetos. Al mismo tiempo, la acreditación legal de su condición migratoria los exime, en teoría, de la exclusión manifiesta en las políticas migratorias, al tiempo que los obliga a cumplir con los deberes establecidos para ese tipo de migración en dicha sociedad. Respecto a esto último, una experiencia de ilegalidad asociada es el no pagar impuestos -que en este estudio no se logró observar como tendencia, aunque sí en casos aislados.

5 En el estudio -y con otros propósitos-, se estableció una tercera tipología en este subgrupo: "los que nacieron en México, lograron acreditar su estancia legal en Estados Unidos y allí permanecieron". En estos casos fue irrelevante el análisis sobre la ilegalidad, al sostener éstos una acreditación legal de la condición migratoria en Estados Unidos por medio de canales migratorios y con apego a las normas establecidas. No obstante, una cuestión significativa fueron los arreglos entre individuos, los cuales sugirieron la utilización del matrimonio como una estrategia para lograr la acreditación legal migratoria. 
Bajo este "deseo de movilidad" manifiesto en esta tipología particular y que acontece por medio de un flujo cotidiano a través de las fronteras, tiene un peso considerable el aspecto económico. El trabajo y los ingresos en el mercado laboral estadounidense permiten una mejor calidad de vida manifiesta en la posesión de bienes diversos. Un problema observado respecto a esa movilidad es el riesgo que implica cruzar las fronteras y el examen que hacen de manera aleatoria las autoridades migratorias. Esto significa, de acuerdo con sus propias prácticas de ilegalidad, perder el privilegio dentro de la selectividad que establece esa política migratoria.

En el caso de "los que nacieron en México y fueron a Estados Unidos bajo una condición irregular que no pudieron cambiar", las experiencias de ilegalidad son más nítidas. De hecho, es esta tipología la que abiertamente incumple con las restricciones impuestas en la política migratoria de Estados Unidos. Además, es sobre la que se han basado la mayoría de los estudios sobre migración indocumentada hacia Estados Unidos -no obstante, no es la única que muestra experiencias de ilegalidad relativas a su trayectoria migrante.

En este caso, las experiencias de ilegalidad no se manifiestan sólo en lo relativo al conjunto de leyes migratorias y sus estipulaciones respecto a la residencia -lo cual incluye la deportación-; sino que, a diferencia de las otras tipologías, también se relacionan con el cruce ilegal acompañado de "coyotes" o tráfico ilegal y con las vivencias que han tenido en el ámbito laboral en Estados Unidos.

Como ya es conocido, bajo esa condición, estos migrantes viven en situación de vulnerabilidad. No obstante, la percepción que predomina en los entrevistados para este estudio es que obtienen una mejoría respecto al ingreso que perciben. En este sentido, los trabajos que refieren están más relacionados con los sectores primario y secundario de la economía estadounidense, al poseer en general una baja calificación educativa y profesional.

Un ejercicio importante, de acuerdo a la exposición a un ambiente no tan atractivo desde el punto de vista social o laboral, fue corroborar las alternativas previas a la migración indocumentada que reflejó esta tipología de migrantes. En su generalidad, fueron migrantes que tomaron la decisión de asentarse ilegalmente bajo una perspectiva de costos-beneficios; la cual no había cambiado después de vivir por varios años en Estados Unidos en condiciones de vulnerabilidad.

En su mayoría emigraron a temprana edad, algunos de ellos siendo adolescentes, motivados por el antecedente de familiares que vivían en las mismas condiciones en Estados Unidos. Además, no fueron migrantes calificados sino que su nivel de estudio se ubicó en su mayoría en el grado de primaria, 
teniendo una baja representación el nivel preparatoria. Aunque la principal motivación para ir a Estados Unidos fue la de buscar trabajo, desconocían en su mayoría el idioma inglés, lo que dificultaba su acceso a puestos mejor remunerados. En este tenor, se ocuparon principalmente en empleos de baja a media retribución, sobre todo, en factorías y áreas de servicios de limpieza o saneamiento vial. El principal uso que le dieron a sus ingresos fue el envío de remesas a sus familiares en México.

Con respecto a la familia, esta migración indocumentada refirió un largo proceso de separación con parientes cercanos, ante la incapacidad para poder viajar por carecer de documentos. Los entrevistados refirieron que no preveían un pronto retorno a México ni por causas familiares; la mayoría explicó que sus familiares continuaban viviendo en las zonas de origen, sobre todo, áreas rurales y semiurbanas.

La principal manera que consideraban para regularizar su condición en Estados Unidos, era la residencia ininterrumpida por más de diez años. Y una estrategia para lograr ese propósito fue documentar su presencia allí; refirieron también que una de las dificultades que encuentran para regularizar su situación migratoria es el desconocimiento y, en ocasiones, el trato que le dan algunos representantes legales, quienes le piden sumas elevadas de dinero para formalizar una petición de este tipo ante las autoridades.

Aunque resultaría necesario un estudio más profundo para corroborar cuán inevitable fue la exposición a esas condiciones de vulnerabilidad en Estados Unidos para la trayectoria de esos migrantes $-y$ hasta qué punto la tradición local o familiar instituyó la alternativa migratoria bajo condiciones particulares de desarrollo que los forzaron a emigrar-, se corrobora en estos casos que es una migración laboral que asumió conscientemente la ilegalidad como una alternativa de cambio. Para algunos, el principal corolario de esa decisión ocurre en el ámbito generacional al tener hijos en aquel territorio, quienes no viven esa misma condición.

Asimismo, la funcionalidad de esa ilegalidad se define mayormente con relación a los ingresos que envían a sus familiares a través de las remesas; de acuerdo a sus propias características son migrantes que intentan evitar las condiciones de vulnerabilidad insertándose en otro contexto donde prevalece la inseguridad humana. Es decir, son migrantes que intentan salir de la vulnerabilidad accediendo a un contexto migratorio selectivo donde se les define como excluibles. En este sentido, en tanto no ocurra un cambio en la acreditación migratoria en Estados Unidos para ellos, no se cumplen los propósitos que los motivaron a acudir a la migración en primer lugar bajo esas condiciones se extiende esa condición de vulnerabilidad o inseguridad humana. 


\section{CONCLUSIONES}

La ilegalidad desde la perspectiva de los migrantes, alude a prácticas asimiladas con un carácter histórico y que usualmente experimentan para lograr sus propósitos. Aunque resultaría necesario ahondar en cómo los contextos particulares de origen que enfrentan fortalecen la decisión de emigrar, aquí se profundiza en cómo esa condición ilegal implica una trasgresión consciente que busca articular procesos y lograr beneficios socioeconómicos en diferentes contextos. Por ello, la ilegalidad desde el punto de vista de los migrantes adquiere un carácter funcional que se justifica en dependencia del lugar de asentamiento y condición migratoria.

La exposición a riesgos particulares y condiciones de vulnerabilidad que esa ilegalidad implica, no es obstáculo para que los migrantes busquen integrar sus propósitos inmediatos y relativos a procesos de movilidad social. No obstante, esa integración indica que la decisión de los migrantes es perentoria y alude a condiciones de desarrollo previas en las que ellos no pueden satisfacer sus necesidades; acudiendo así a la migración como un recurso que intenta cubrir las carencias que enfrentan.

La integración también revela la independencia de ese carácter funcional de las decisiones y acciones de los migrantes respecto a las políticas restrictivas en materia migratoria. El principal propósito de esa funcionalidad es la movilidad humana que intenta incorporarse a contextos con -así entendidos-, mejores beneficios y donde el acceso al trabajo y los ingresos operan como catalizadores de la trayectoria migrante. Así, la búsqueda de oportunidades económicas a través de la migración, en los casos que se dirigen hacia un territorio donde prevalece una exposición a condiciones de incertidumbre o riesgo, evidencia un rasgo particular de inseguridad humana donde las acciones de naturaleza ilegal son respuestas decisivas que se relacionan con vulnerabilidad en la sociedad de origen.

En ese contexto esas prácticas asimiladas y que fueron antes mencionadas, representan un proceso de diversificación de las opciones para migrantes en desventaja dentro de un contexto restrictivo. En lo relativo a las trayectorias de los grupos escogidos y a partir de los incentivos que predominan en su decisión, resulta poco probable que disminuya la importancia de esa diversificación. Esto es, la funcionalidad del carácter ilegal de sus decisiones determina los ciclos de reproducción de la trayectoria migrante. Estos ciclos de reproducción ocurren en ambos lados de la frontera.

Esto último es relevante para considerar el alcance de las políticas restrictivas prevalecientes en las sociedades de acogida. Máxime, porque éstas tienden 
a obviar -como también lo hacen los estereotipos negativos sobre la migración- la existencia de procesos de integración alternos sostenidos por intereses al interior de los éxodos y que se corresponden con la demanda de mano de obra barata, que también existe en aquellos contextos. La restricción a migrantes no favorecidos no coarta el deseo de movilidad presente en ellos. La selectividad no es una política que induzca a disminuir el proceso migratorio porque no contempla las causas reales que determinan los éxodos.

Algunas de las ideas contenidas en este trabajo, ayudan a explicar los éxodos recientes y el significado que tiene la ilegalidad para diásporas que enfrentan no pocos obstáculos. No obstante a ello, están convencidas que la migración y la transgresión circunstancial de las normas migratorias de los estados-nación, podría ser una solución a los problemas que enfrentan. De esta forma, el principal aporte de este artículo es resaltar el carácter perentorio de las decisiones de los migrantes, desde el cual emanan particulares significados de esa ilegalidad. Aspecto que necesariamente debe ser considerado en el rediseño de políticas migratorias transnacionales a nivel global y en atención a las condiciones desiguales de desarrollo.

\section{BIBLIOGRAFÍA}

Alvites, A. (2019), "Migraciones internacionales, fronteras y estados. ¿Cómo interpretar el régimen de frontera desde América del Sur?", Desafíos, vol. 31, núm. 1, DOI <http://dx.doi.org/10.12804/revistas.urosario.edu.co/desafios/a.6231>

Aragonés, A. y Salgado, U. (2015), "La migración laboral México-Estados Unidos a veinte años del Tratado de Libre Comercio de América del Norte", Revista Mexicana de Ciencias Politicas y Sociales, año LX, núm. 224, DOI <http://dx.doi.org/10.1016/S0185-1918(15)30011-8>

Castels, S. (2003), "La política internacional de la migración forzada", Migración y Desarrollo, núm. 1, Zacatecas, Doctorado en Estudios del Desarrollo, octubre.

(2006), "Factores que hacen y deshacen las políticas migratorias", en A. Portes y J. DeWind (coords.), Repensando las migraciones. Nuevas perspectivas teóricas y empiricas, Colección América Latina y el Nuevo Orden Mundial, México, Instituto Nacional de Migración, Universidad Autónoma de Zacatecas y Miguel Ángel Porrúa.

(2014), "Las fuerzas tras la migración global", Revista Mexicana de Ciencias Politicas y Sociales, año LIX, núm. 220, enero-abril, DOI <https:// doi.org/10.1016/S0185-1918(14)70806-2> 
Cornelius, W. y Aguayo, S. (1978), "La migración ilegal mexicana a los Estados Unidos, conclusiones de investigaciones recientes, implicaciones políticas y prioridades de investigación”, Foro Internacional, vol. 18, núm. 3, Ciudad de México, colmex, enero-marzo.

Delgado Wise, R. (2018), "Reflexiones en torno a la teoría y la práctica de la relación migración y desarrollo: una perspectiva desde el Sur", Migración y Desarrollo, vol. 16, núm. 31, Doctorado de Estudios del Desarrollo, Zacatecas, Universidad Autónoma de Zacatecas, segundo semestre.

Faist, T. y Gerdes, J. (2006), "La doble ciudadanía como un proceso dependiente de la trayectoria", en A. Portes y J. DeWind (coords.), Repensando las migraciones. Nuevas perspectivas teóricas y empiricas, Colección América Latina y el Nuevo Orden Mundial, Zacatecas, Instituto Nacional de Migración, Universidad Autónoma de Zacatecas y Miguel Ángel Porrúa.

Furtado, C. (2001), La economía latinoamericana. Formación histórica y problemas contemporáneos, España, Siglo XXI Editores.

Galindo, S. (2019), "Las palabras importan: representación de los inmigrantes mexicanos en periódicos de México y Estados Unidos", Migraciones Internacionales, vol. 10, DOI <http://dx.doi.org/10.33679/rmi.v1i1.2024>

Glick Schiller, N., Basch, L. y Szanton, C. (1995), "From immigrant to transmigrant: theorizing transnational migration", Anthropological Quarterly, vol. 68, núm. 1, DOI <https://doi.org/10.2307/3317464>

Lomelí, L. y Vázquez, L. (2016), "Cambio estructural y migración. El caso de México", Economía, vol. 13, núm. 39, México, unam, Instituto de Investigaciones Económicas, septiembre-diciembre. Recuperado de <http:// www.revistas.unam.mx/index.php/ecu/article/view/57074/50626>

Massey, D. y Capoferro, C. (2006), "La medición de la migración indocumentada", en A. Portes y J. DeWind (coords.), Repensando las migraciones. Nuevas perspectivas teóricas y empiricas, Colección América Latina y el Nuevo Orden Mundial, Zacatecas, Instituto Nacional de Migración, Universidad Autónoma de Zacatecas y Miguel Ángel Porrúa.

Munguía Salazar, A. (2015), La política migratoria en los Estados Unidos, México, Facultad de Derecho y Ciencias Sociales, Benemérita Universidad Autónoma de Puebla, Piso 15 Editores.

Roldán, G. (2015), "Migración México-Estados Unidos: paradoja liberal renovada del tLCan", Problemas del Desarrollo. Revista Latinoamericana de Economía, vol. 181, núm. 46, DOI <http://dx.doi.org/10.22201/ iiec.20078951e.2015.181.48823> 
Vázquez, M. (2015), "Migración indocumentada e integración entre México y Estados Unidos. Razones y trayectorias”, Norteamérica, vol. 10, núm. 2, DOI <https://doi.org/10.20999/nam.2015.b004>

Villareal, M. (2019), La construcción de México a partir de la prensa internacional: una mirada de la migración desde el enfoque del The New York Times (Tesis de grado), México, Facultad de Ciencias Políticas y Sociales, Universidad Autónoma del Estado de México. Recuperado de <http://ri.uaemex. $\mathrm{mx} / \mathrm{handle} / 20.500 .11799 / 99879>$

Zenteno, R. y Massey, D. (1999), “Especificidad vs. representatividad: enfoques metodológicos sobre el estudio de la migración mexicana hacia los Estados Unidos”, Estudios Demográficos y Urbanos, vol. 14, núm. 1, DOI $<$ http://dx.doi.org/10.24201/edu.v14i1.1038> 
